\title{
López Bustos, Francisco L. (Dir.) y Bombillar Sáenz, Francisco Miguel (Coord.) (2018). Régimen jurídico del voluntariado y de la cooperación al desarrollo. Granada: Editorial Comares
}

ISBN:978-84-9045-378

\section{Por Elena Avilés Hernández ${ }^{1}$}

\begin{abstract}
La obra efectúa un completo y detallado análisis del régimen jurídico del voluntariado y la cooperación al desarrollo. En sus múltiples capítulos, recoge y clarifica las cada vez más diversas vertientes que componen su regulación. Al mismo tiempo, es también un homenaje póstumo a Rafael Barranco Vela, una de las personalidades más relevantes y pioneras en esta materia.
\end{abstract}

Palabras clave: Régimen jurídico, voluntariado, cooperación al desarrollo

La obra Régimen jurídico del voluntariado y de la cooperación al desarrollo realiza un profundo análisis de los múltiples aspectos que componen la regulación de esta materia. A modo introductorio, Bensusan Martín (pp.1-70) lleva a cabo una aproximación a los conceptos y antecedentes históricos de algunas de las definiciones más significativas de esta temática: voluntariado, voluntario o cooperación al desarrollo. Además, esclarece la organización administrativa estatal y autonómica, así como su regulación actual. Este capítulo facilita al lector una mayor comprensión de la disciplina investigada en el texto. Ahondando más en el tema, Pérez Miras (pp.71-95), a partir de la Ley 43/2015, de 9 de octubre y la Ley 45/2015, de 14 de octubre, realiza un recorrido a lo largo del marco normativo de las entidades de voluntariado y del Tercer Sector de Acción Social. El objetivo último es esclarecer el régimen jurídico sobre el que se sustentan. A continuación, y en un intento de presentar a los sujetos que intervienen en este asunto, Bombillar Sáenz (pp.97-136) profundiza en el estatuto jurídico de los voluntarios, las entidades de voluntariado y los destinatarios de la acción voluntaria. El hecho de que por primera vez los beneficiarios aparezcan regulados de forma expresa en una ley, permite cerrar el círculo de sujetos e instituciones que se interrelacionan en este ámbito. Para completar los diferentes pilares sobre los que se asientan las entidades del Tercer Sector de Acción Social, Martín Rodríguez (pp.137-155) se centra en las particularidades del régimen fiscal de las ONG como excepción al régimen general. Destaca los beneficios que le otorga a las entidades sin ánimo de lucro el poder acogerse al régimen fiscal especial reflejado en la Ley 40/2002, de 23 de diciembre, frente a aquellas que, por no cumplir los requisitos exigidos, no pueden llevarlo a cabo.

La siguiente sección de la obra permite un mejor entendimiento de las singularidades de cada una de las modalidades de voluntariado recogidas en la Ley 45/2015, de 14 de octubre, que de primeras pudieren pasar inadvertidas; así, Burgos Garrido (pp.157-192) trata el voluntariado de acción social a partir de su definición,

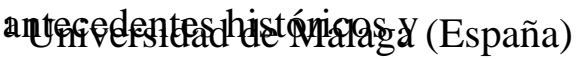

Contacto: elenaavileshernandez@uma.es 
marco normativo, para concluir con una exposición de las particularidades (y dificultades) de su régimen jurídico debido a las múltiples necesidades de los colectivos a los que debe atender. Por su parte, Gómez Vallecillo (pp.193-216) aborda diferentes cuestiones que versan sobre el voluntariado con personas con discapacidad. En primer lugar, contextualiza las actividades enfocadas a este colectivo en relación con el resto de las áreas de voluntariado; seguidamente, apunta dos novedades incluidas en la nueva regulación de 2015: por un lado, el voluntariado deportivo y su incidencia en el ámbito de la discapacidad y, por otro, el nuevo marco jurídico que contempla a las personas con discapacidad como sujetos activos de cualquier programa de voluntariado. Otra de las nuevas categorías jurídicas que recoge la Ley de Voluntariado y que explica Burgos Garrido (pp.217-238) es el voluntariado sociosanitario, y lo realiza utilizando como ejemplo paradigmático la mundialmente conocida Cruz Roja. De esta forma acerca al lector a una realidad que, aunque antes no era desconocida, puesto que estaba englobada en el voluntariado social, ahora adquiere entidad propia. Una de las novedades que considero especialmente enriquecedora en cuanto a su singularidad, y que presenta Luna Quesada (pp.239-260) es el voluntariado comunitario. Surge como consecuencia de lo acontecido tras la recesión económica de 2008 y otorga un nuevo significado al término, pasando de una definición tradicional de carácter individual a una acción colectiva y reivindicativa que busca promover la participación efectiva de los ciudadanos en la toma de decisiones. Seguidamente, Benlloch Doménech y Sarrión Esteve (pp.261-271) se ocupan del voluntariado educativo, tratando además de cuantificar el cómputo de personas que participan en estas intervenciones, algo realmente complejo de medir. Confiere además una dificultad añadida el hecho de que esta tipología converge con los programas de aprendizaje-servicio del propio sistema educativo u otras actividades de enseñanza no formal.

Profundizando en la materia de capítulos anteriores, De la Plata Caballero, López Chaves y Huete Lizarazu (pp.273-291) se centran en el uso de la figura del voluntario deportivo en los clubes de categorías no profesionales o la cantera y en la problemática que ello suscita; la distinción entre la noción de voluntario y de trabajador incide no solamente en su retribución, sino también en la normativa aplicable. A continuación, Sánchez-Mesa Martínez (pp.311-349) analiza el papel del voluntariado cultural como complemento a la intervención realizada por la propia Administración Pública para garantizar derechos como el acceso a la cultura o la participación en la vida en sociedad. Es fundamental resaltar el papel tan importante que ostenta la ciudadanía como agente que suple las carencias legislativas. La obra no deja de lado un elemento tan esencial como es el voluntariado de carácter ambiental. López Bustos (pp.351-380) destaca su papel, incluso antes del surgimiento de la conciencia ecológica, a pesar de no existir mención alguna en los instrumentos internacionales. Pese al rol transcendental que ostenta para la consecución de objetivos ambientales, es un término desconocido por parte de la sociedad. De ahí la importancia de resaltar el potencial que tiene la solidaridad colectiva para lograr este propósito. A pesar de que el art. 6 de la Ley 43/2015 recoge como último ámbito de actuación del voluntariado el de protección civil, cabe decir que esta actúa con carácter supletorio, ya que se encuentra ampliamente regulado a nivel estatal y autonómico. Partiendo de esta idea, Navajas Trujillo y Bombillar Sáenz (pp.381-398) analizan la normativa reguladora en Andalucía, mostrando al lector las organizaciones más representativas: las agrupaciones locales de voluntarios de protección civil.

Fuera de la enumeración planteada por la Ley de Voluntariado y configurándose como enlace respecto al tema que se desarrolla a continuación, existe una actividad cada vez 
más conocida y que a veces puede entenderse como un subproducto de la cooperación al desarrollo: el turismo solidario. Román Márquez (pp.293-309) aclara el concepto para evitar la confusión entre este y la figura del cooperante, dilucida sus diferencias y, además, advierte de algunas de las dificultades que presenta. Continuando con el intento de distinguir tipologías que a simple vista pudieran parecer similares, Durán Ruiz (pp.399-436) se encarga de realizar un exhaustivo análisis de la figura del cooperante, diferenciándola así de la revisada hasta entonces en la obra. Sin embargo, y a pesar de estar reguladas de forma autónoma, sigue existiendo problemas a la hora de aplicar cada una de ellas en la práctica.

Otro de los aspectos relevantes que los autores del texto no han querido olvidar es el papel de las universidades en materia de voluntariado y cooperación al desarrollo. De ahí que Maroto Martos y Barrera Rosillo (pp.447-477) se encarguen de exponer al lector la importancia de esta institución en el impulso del voluntariado. En este caso, haciendo referencia a la actividad que realiza la Universidad de Granada y al perfil de los voluntarios que colaboran con UGR Solidaria. El libro rescata también una contribución publicada por Barranco Vela (pp.437-446) en el año 2011 donde, además de exponer el origen y marco legal del voluntariado en España, destaca el progresivo y cada vez más importante papel de las universidades en este asunto. La inclusión del capítulo no es sino un reflejo del cariño y respeto que, específicamente el grupo de investigación y de forma generalizada la Facultad de Derecho de la Universidad de Granada, tienen a su compañero, fruto de la labor realizada durante tantos años de trabajo.

Para completar el texto, Ansón Ruiz (pp.479-492), Lara y Villena (pp.493-499) relatan dos experiencias en materia de cooperación al desarrollo que muestran una visión práctica de la teoría expuesta anteriormente. El primero, se centra en el ámbito de la salud a través de Farmamundi, una ONG internacional que promociona la salud integral y ayuda farmacéutica a los países menos favorecidos. Los segundos, cuentan su vivencia en el ámbito de la educación con Ahoringa Vuelcapeta, una fundación enfocada en el desarrollo y promoción humana de los jóvenes de Bellavista, Bolivia. Lo destacable de ambos casos es el papel del voluntario como nexo imprescindible de unión con la sociedad civil.

Como conclusión cabe decir que la Ley de Voluntariado define y amplía un concepto un tanto difuso hasta entonces, además de concretar los diferentes ámbitos de actuación dentro de los cuales se enmarca esta figura. Sin embargo, este libro va más allá de un mero análisis de una novedosa regulación, ya que da voz a aquellos actores o entidades que, por no enmarcarse en lo tradicionalmente conocido como voluntariado, no tienen cabida en esta concepción legal. Por todo lo expuesto anteriormente, cabe decir que se trata de una obra de referencia para toda la comunidad docente o investigadora interesada en abordar el tema del voluntariado y la cooperación al desarrollo desde una perspectiva multidisciplinar. Por ello espero que esta reseña sea útil para lograr este propósito. 